Gut and Liver, Vol. 10, No. 4, July 2016, pp. 562-568

\title{
Comparison of the Efficacies of Parenteral Iron Sucrose and Oral Iron Sulfate for Anemic Patients with Inflammatory Bowel Disease in Korea
}

\author{
Yoo Min $\mathrm{Han}^{1}$, Hyuk Yoon ${ }^{2}$, Cheol Min Shin², Seong-Joon Koh ${ }^{3}$, Jong Pil Im ${ }^{1}$, Byeong Gwan Kim² ${ }^{3}$ Joo Sung Kim ${ }^{1}$, and Hyun \\ Chae Jung \\ ${ }^{1}$ Department of Internal Medicine and Liver Research Institute, Seoul National University College of Medicine, Seoul, ${ }^{2}$ Department of Internal \\ Medicine, Seoul National University Bundang Hospital, Seongnam, and ${ }^{3}$ Department of Internal Medicine, Seoul National University Boramae \\ Medical Center, Seoul, Korea
}

See editorial on page 487.

Background/Aims: The optimal route for iron administration in anemic patients with inflammatory bowel disease (IBD) has not been determined. The aim of this study was to compare the efficacies of parenteral and oral iron therapy in IBD patients in Korea. Methods: A retrospective multicenter study was performed. Patients who had been administered parenteral iron were matched to the controls with oral iron at a 1:1 ratio according to age, sex, and type of IBD. Results: Patients that received parenteral iron exhibited increases in hemoglobin levels of $\geq 20 \%$ from the baseline at lower doses and in shorter durations $(p=0.034$ and $p=0.046$, respectively). In the multivariate analysis, parenteral iron therapy appeared to be more efficient than oral iron therapy, but this difference was not statistically significant (hazard ratio [HR], 1.552; 95\% confidence interval [Cl], 0.844 to 2.851; $\mathrm{p}=0.157)$. Patients with ulcerative colitis responded better to iron therapy than those with Crohn's disease (HR, 3.415; $95 \% \mathrm{Cl}, 1.808$ to $6.450 ; \mathrm{p}<0.001$ ). Patients with an initial hemoglobin level of $10 \mathrm{~g} / \mathrm{dL}$ or higher responded poorly to iron therapy (HR, 0.345; 95\% $\mathrm{Cl}, 0.177$ to $0.671 ; \mathrm{p}=0.002$ ).

Conclusions: Parenteral iron therapy appears to be more efficient than oral iron therapy. Physicians should focus on the iron deficiency of IBD patients and consider parenteral iron supplements in appropriate patient groups. (Gut Liver 2016;10:562-568)

Key Words: Crohn disease; Inflammatory bowel diseases; Anemia, iron-deficiency; Parenteral iron; Colitis, ulcerative

\section{INTRODUCTION}

Anemia is common in patients with inflammatory bowel disease (IBD). Previous study reported that $26 \%$ of patients with Crohn's disease (CD) and 37\% of patients with ulcerative colitis (UC) had anemia, ${ }^{1}$ and anemia is associated with significant morbidity and mortality. ${ }^{2-4}$ Many factors contributed to the development of anemia, for instance, iron, vitamin $B_{12}$ and folic acid deficiencies, effect of proinflammatory cytokines, hemolysis, and myelosuppression due to drug therapy. Among them, iron deficiency anemia (IDA) is the most common cause of anemia in IBD patients. Chronic blood loss through gastrointestinal tract and malabsorption of iron when the proximal digestive tract is affected by IBD caused iron deficiency., ${ }^{5,6}$ However, IDA was underdiagnosed so that only one third of patients with anemia undertook further diagnostic tests. ${ }^{7}$ Furthermore, treatment of anemia was often neglected by physicians, so only $45.7 \%$ of patients diagnosed with IDA received iron supplements. ${ }^{7}$

Oral administration of iron was the conventional approach in the treatment of IDA. However, bioavailability of oral iron is low and intestinal absorption is compromised in IBD patients due to bowel inflammation and increased hepcidin level. Therapeutic effect of oral iron supplement is relatively slow so it took at least six months to replenish iron stores completely. ${ }^{8}$ Also, oral iron induced gastrointestinal discomfort and due to poor tolerability, $66 \%$ patients who took oral supplements were dissatisfied with their treatment. ${ }^{9}$ Recent meta-analysis showed that parenteral iron therapy is more efficient and better tolerated by patients. ${ }^{10,11}$ American and European guideline recommended parenteral iron in patients with severe anemia (hemoglobin $[\mathrm{Hb}]<10 \mathrm{~g} / \mathrm{dL}$ ), with intolerance or inadequate response to oral iron, or with concomitant erythropoietin (Epo) treatment and/or

Correspondence to: Hyuk Yoon

Department of Internal Medicine, Seoul National University Bundang Hospital, 82 Gumi-ro 173beon-gil, Bundang-gu, Seongnam 13620, Korea

Tel: +82-31-787-7042, Fax: +82-31-787-4051, E-mail: bodnsoul@daum.net

Received on August 3, 2015. Revised on September 10, 2015. Accepted on October 5, 2015. Published online March 30 , 2016

pISSN 1976-2283 eISSN 2005-1212 http://dx.doi.org/10.5009/gnl15373

@) This is an Open Access article distributed under the terms of the Creative Commons Attribution Non-Commercial License (http://creativecommons.org/licenses/by-nc/4.0) which permits unrestricted non-commercial use, distribution, and reproduction in any medium, provided the original work is properly cited. 
presence of active IBD. ${ }^{12,13}$ However, parenteral iron therapy in Korea is restricted to the patients with $\mathrm{Hb}<8 \mathrm{~g} / \mathrm{dL}$ and intolerance to oral iron, needs for urgent iron therapy with bleeding and serum ferritin $<12 \mathrm{ng} / \mathrm{mL}$ or transferrin saturation $<15 \%$. This criteria for parenteral iron administration was compelled by national health insurance service. Therefore, numerous IDA patients with IBD could not receive active treatment with parenteral iron supplements.

All the current studies which compare the effect of oral and parenteral iron therapy were performed in America and Europe. ${ }^{14-17}$ Little information is available for IBD patients with Asian ethnicity. ${ }^{18}$ The aim of this study was to compare the efficacy of parenteral and oral iron therapy in IBD patients in Korea. We planned to verify whether parenteral iron therapy was superior to oral iron therapy in terms of required time and dose to the response. Furthermore, we tried to figure out the factors that affect the treatment outcome of iron therapy by multivariate analysis.

\section{MATERIALS AND METHODS}

\section{Patients}

Patients who were diagnosed as IBD between 2005 and 2012 at Seoul National University Hospital, Seoul National University Bundang Hospital, and Seoul National University Boramae Medical Center were screened. IBD was diagnosed according to clinical, endoscopic, radiological, and histological criteria. ${ }^{19,20}$ We reviewed electronic medical records of these patients. Among them, patients with anemia (Hb lower than $13.0 \mathrm{~g} / \mathrm{dL}$ in men, $12.0 \mathrm{~g} / \mathrm{dL}$ in women) were identified. We included the patients with microcytic hypochromic anemia (mean corpuscular volume $<80 \mathrm{fL}$ and mean corpuscular $\mathrm{Hb}<27 \mathrm{pg}$ ). Eligible patients had to be 16 years of age or older. Exclusion criteria comprised pregnancy or lactation, clinically significant overt bleeding, surgery with relevant blood loss (Hb decrease $>2 \mathrm{~g}$ / $\mathrm{dL}$ ), myelodysplastic syndrome, active malignancy or chronic renal failure.

Patients who had been administered over $400 \mathrm{mg}$ of parenteral element iron were selected. The available parenteral iron prescription in these hospitals was ferric hydroxide sucrose complex (Venoferrum; Nycomed, Zurich, Switzerland) which contained $100 \mathrm{mg}$ of elemental iron per ample. Treatment schedules were not consistent among the patients, some treated as daily injection for several days, and others treated as weekly or monthly injection schedule.

\section{Controls}

Among the patients with IBD and IDA, those who had been administered over $4,000 \mathrm{mg}$ oral iron were selected. Bioavailability of oral iron is esteemed as $10 \%,{ }^{21}$ therefore, we considered that parenteral injection of $1 \mathrm{mg}$ elemental iron were equivalent to the orally administered $10 \mathrm{mg}$ of elemental iron.
The available oral iron prescription in our hospitals was ferrous sulfate complex (Feroba; Bukwang, Seoul, Korea) which contained $80 \mathrm{mg}$ of elemental iron per tablet. Ferrous sulfate tablet was prescribed to be taken twice a day before meal. The controls were matched at a fixed 1:1 ratio according to age, sex, and type of IBD.

\section{Efficacy measures}

Age, sex, extent and behavior of disease, presence of perianal lesions, operation history, and concurrent medication were reviewed. Baseline $\mathrm{Hb}$ level were also reviewed.

The primary efficacy measure was the rise in $\mathrm{Hb} \geq 2 \mathrm{~g} / \mathrm{dL}$ from the baseline. The secondary efficacy measure was the rise in $\mathrm{Hb} \geq 20 \%$ from the baseline. The total dose of iron and time required to accomplish the end points were also evaluated.

\section{Statistical analysis}

The data were analyzed using IBM SPSS version 20.0 (IBM Corp., Armonk, NY, USA). Continuous variables were analyzed using the Student t-tests or Mann-Whitney U tests and categorical variables were analyzed using chi-squared tests or Fisher exact tests.

The life table method was used to compare the efficacy between the parenteral and oral iron therapy groups. Efficacy was assessed from two points of view, total dose of iron required and time spent to achieve the end point.

Covariates evaluated included age, gender, type of IBD, route of iron treatment, and baseline $\mathrm{Hb}$. Multivariate Cox regression analysis were used to verify the factors that affect the treatment response. Patients were censored when they discontinued iron therapy due to follow-up loss, ineffectiveness, or adverse event to iron therapy, even though treatment outcomes were not accomplished. Variables with p-values less than 0.20 in the univariate analysis were included to estimate the overall treatment effect. Because demographic data of age and sex were considered clinically fundamental and important, we included these variables in multivariate analysis irrespective of $p$-value. The $p$ values less than 0.05 were considered statistically significant in the multivariate analysis.

\section{Ethical considerations}

The study was approved by the International Review Board of Seoul National University Hospital (IRB number: J-1406-001580) and was conducted in accordance with the Declaration of Helsinki.

\section{RESULTS}

\section{Baseline characteristics}

Among IBD patients diagnosed with IDA, 41 patients were treated with more than $400 \mathrm{mg}$ of parenteral iron. Indications for parenteral iron prescription were listed in Table 1. Main 
Table 1. Indication of Parenteral Iron Therapy

\begin{tabular}{lc}
\hline Cause of parenteral administration & No. (\%) \\
\hline Intolerance to oral iron & $10(24)$ \\
Nonresponse to oral iron & $9(22)$ \\
Severe anemia & $9(22)$ \\
Severe intestinal disease activity & $9(22)$ \\
Patient's requests & $1(3)$ \\
Others & $3(7)$ \\
\hline
\end{tabular}

reason was intolerance to oral iron therapy (24\%), and others were non-response to oral iron (22\%), severe anemia (22\%), and severe intestinal disease activity (22\%).

Controls were matched with a 1:1 ratio according to age, sex, and type of IBD. Twenty-seven patients (66\%) were diagnosed as $\mathrm{CD}$, and 14 (34\%) were UC in each group. Between the two groups, there was no significant difference in baseline characteristics (Table 2).

Initial $\mathrm{Hb}$ was significantly lower in parenteral iron group than oral iron group ( $8.4 \mathrm{~g} / \mathrm{dL}$ vs $9.8 \mathrm{~g} / \mathrm{dL}, \mathrm{p}<0.001)$. Treatment duration was shorter in parenteral iron group but it was not statistically significant ( 4 weeks vs 12 weeks, $p=0.251$ ). Total dose of oral iron was converted to parenteral dose as $1 / 10$ ratio, in other words, $10 \mathrm{mg}$ of oral iron was considered equivalent to $1 \mathrm{mg}$ parenteral iron. Total dose of iron administered was significant lower in parenteral iron group (600 mg vs $1,120 \mathrm{mg}$, $\mathrm{p}=0.001$ ), however, there was no significant difference in weekly dose of iron (125 mg vs $112 \mathrm{mg}, \mathrm{p}=0.162$ ) (Table 3).

\section{Efficacy of iron therapy}

The life table method was used to compare the efficacy of parenteral and oral iron. The primary efficacy measure was the rise in $\mathrm{Hb} \geq 2 \mathrm{~g} / \mathrm{dL}$ from the baseline. Among 41 patients in each group, 25 patients (61.0\%) in the parenteral iron group achieved the primary end point, meanwhile, 34 patients (82.9\%) out in the oral iron group accomplished the goal. Patients in parenteral iron group had tendency to acquire the primary end point in the lower iron dose, but it was not statistically significant $(p=0.060)$ (Fig. 1). Patients in parenteral iron group tended to achieve the primary end point in shorter treatment duration, however, it was also not statistically significant ( $p=0.087$ ) (Fig. 2).

The secondary efficacy measure was the rise in $\mathrm{Hb} \geq 20 \%$ from the baseline. Among the 41 patients in each group, 25 patients (61.0\%) in parenteral iron group and 34 patients (82.9\%) out in oral iron group achieved the secondary end point. Total iron required to acquire primary end point was much lower in parenteral iron group ( $\mathrm{p}=0.034)$ (Fig. 3). Parenteral iron group achieved the secondary end point more quickly than oral iron group ( $\mathrm{p}=0.046$ ) (Fig. 4).
Table 2. Baseline Characteristics

\begin{tabular}{|c|c|c|c|}
\hline Characteristic & $\begin{array}{c}\text { Parenteral } \\
\text { iron }(n=41)\end{array}$ & $\begin{array}{l}\text { Oral iron } \\
(n=41)\end{array}$ & p-value \\
\hline \multicolumn{4}{|l|}{ Crohn's disease $(n=54)$} \\
\hline Female sex & $14(52)$ & $14(52)$ & $>0.999^{*}$ \\
\hline Age, yr & $35.0 \pm 11.7$ & $33.7 \pm 11.9$ & $0.694^{\dagger}$ \\
\hline Age at diagnosis, yr & & & $0.108^{*}$ \\
\hline $\mathrm{A} 1 \leq 16$ & $6(22)$ & $1(4)$ & \\
\hline A2 $17-40$ & $19(70)$ & $22(81)$ & \\
\hline A3 $>40$ & $2(8)$ & $4(15)$ & \\
\hline Disease location & & & $0.741^{*}$ \\
\hline L1 Terminal ileum & $8(30)$ & $7(26)$ & \\
\hline L2 Colon & $3(11)$ & $5(18)$ & \\
\hline L3 Ileocolon & $16(59)$ & $15(56)$ & \\
\hline Upper gastrointestinal tract & $1(4)$ & $1(4)$ & $>0.999^{\ddagger}$ \\
\hline Disease behavior & & & $0.188^{*}$ \\
\hline B1 (NS-NP) & $5(18)$ & $11(41)$ & \\
\hline B2 (structuring) & $11(41)$ & 9 (33) & \\
\hline B3 (penetrating) & $11(41)$ & $7(26)$ & \\
\hline Perianal disease & $6(22)$ & $11(41)$ & $0.143^{*}$ \\
\hline Operation history & $10(37)$ & $10(37)$ & $>0.999^{*}$ \\
\hline \multicolumn{4}{|l|}{ Medication } \\
\hline 5-Aminosalicylic acid & $20(74)$ & $20(74)$ & $1.000^{*}$ \\
\hline Thiopurines & $12(44)$ & $15(56)$ & $0.414^{*}$ \\
\hline Steroid & $13(48)$ & $9(33)$ & $0.268^{*}$ \\
\hline Anti-TNF- $\alpha$ & $1(3.7)$ & $5(18.5)$ & $0.192^{\ddagger}$ \\
\hline \multicolumn{4}{|l|}{ Ulcerative colitis $(n=28)$} \\
\hline Female sex & $7(50)$ & $7(50)$ & $>0.999^{*}$ \\
\hline Age, yr & $39.7 \pm 13.4$ & $40.0 \pm 14.6$ & 0.963 \\
\hline Age at diagnosis, yr & & & $0.574^{*}$ \\
\hline $\mathrm{A} 1 \leq 16$ & 0 & $1(7)$ & \\
\hline A2 $17-40$ & $9(64)$ & $9(64)$ & \\
\hline A $3>40$ & $5(36)$ & $4(29)$ & \\
\hline Disease location & & & $0.482^{*}$ \\
\hline E1 Proctitis & 0 & $1(7)$ & \\
\hline E2 Left side colitis & $6(43)$ & $4(29)$ & \\
\hline E3 Pancolitis & $8(57)$ & $9(64)$ & \\
\hline Operation history & $4(29)$ & $4(29)$ & $>0.999^{\ddagger}$ \\
\hline \multicolumn{4}{|l|}{ Medication } \\
\hline 5-Aminosalicylic acid & $10(71)$ & $6(43)$ & $0.127^{*}$ \\
\hline Thiopurines & $4(29)$ & $2(14)$ & $0.648^{\ddagger}$ \\
\hline Steroid & $5(36)$ & $8(57)$ & $0.256^{*}$ \\
\hline Anti-TNF- $\alpha$ & 0 & 0 & NA \\
\hline
\end{tabular}

Data are presented as number $(\%)$ or mean \pm SD.

NS-NP, nonstricturing-nonpenentrating; Anti-TNF- $\alpha$, anti-tumor necrosis factor $\alpha$; NA, not applicable.

${ }^{*}$ Chi-square test; ${ }^{\dagger}$ Student t-test; ${ }^{\ddagger}$ Fisher exact test. 
Table 3. Initial Hemoglobin and Treatment Profile

\begin{tabular}{lccr}
\hline & Parenteral iron $(\mathrm{n}=41)$ & Oral iron $(\mathrm{n}=41)$ & $\mathrm{p}$-value \\
\hline Total dose of iron, mg & $600(400-1,000)$ & $1,120(560-1,848)$ & $0.001^{*}$ \\
Weekly dose of iron, mg & $125(46-200)$ & $112(112-112)$ & $0.162^{*}$ \\
Treatment duration, wk & $4(4-12)$ & $12(7-17)$ & $0.251^{*}$ \\
Initial hemoglobin, g/dL & $8.4(7.5-9.8)$ & $9.8(8.7-10.6)$ & $<0.001^{*}$ \\
\hline
\end{tabular}

Data are presented as median (interquartile range).

*Mann-Whitney U test.

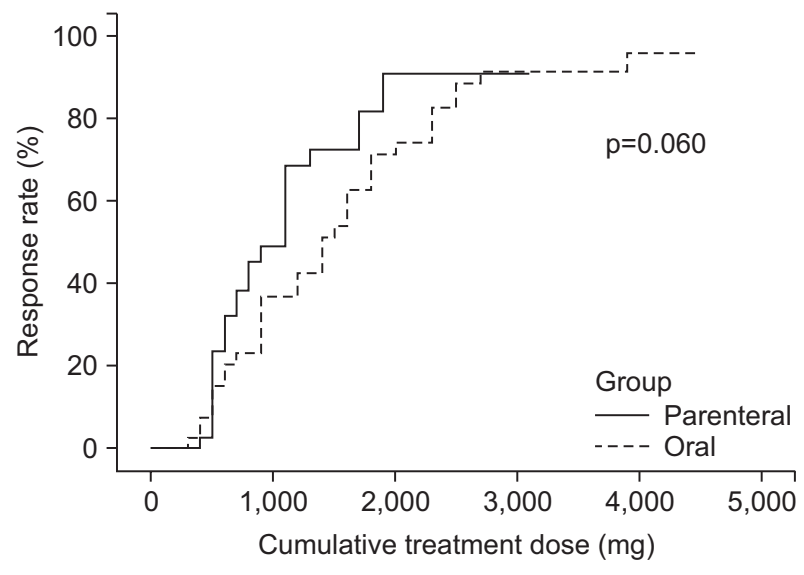

Fig. 1. Comparison of the efficacies of parenteral and oral iron treatment according to the total dose required to achieve $\mathrm{a} \geq 2 \mathrm{~g} / \mathrm{dL}$ increase in hemoglobin from the baseline. The data were analyzed using the life table method.

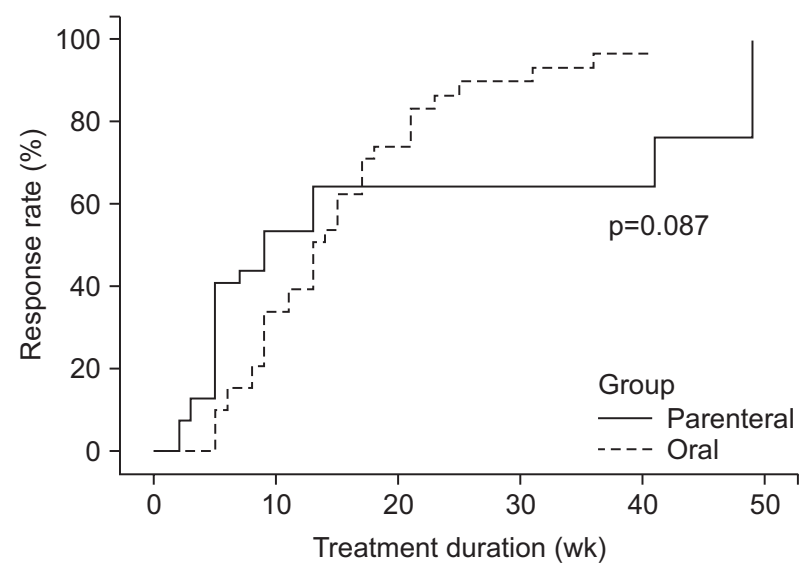

Fig. 2. Comparison of the efficacies of parenteral and oral iron treatment according to the time spent to achieve $a \geq 2 \mathrm{~g} / \mathrm{dL}$ increase in hemoglobin from the baseline. The data were analyzed using the life table method.

\section{Multivariate assessment}

Covariates evaluated were age, gender, type of IBD, route of iron treatment, and baseline $\mathrm{Hb}$, and all statistically significant covariates were used to estimate the overall treatment effect.

First, we evaluated the factors associated with the primary

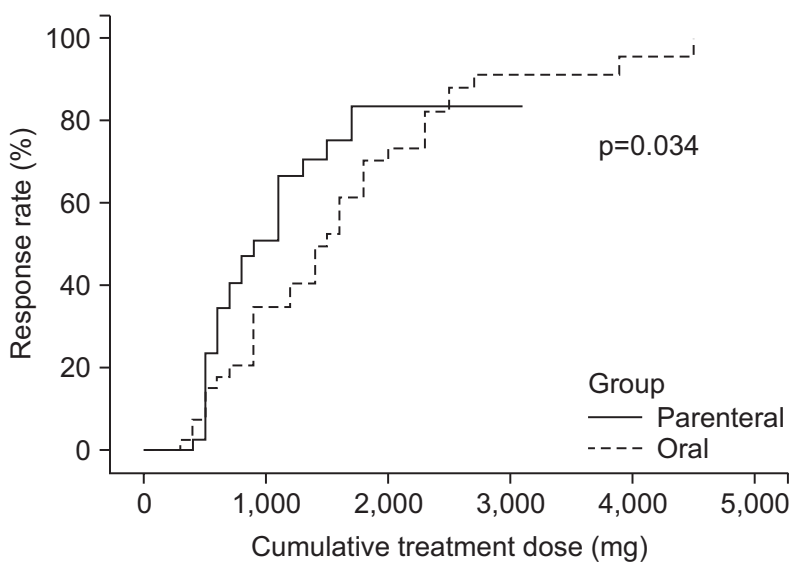

Fig. 3. Comparison of the efficacies of parenteral and oral iron treatment according to the total dose required to achieve a $\geq 20 \%$ increase in hemoglobin from the baseline. The data were analyzed using the life table method.

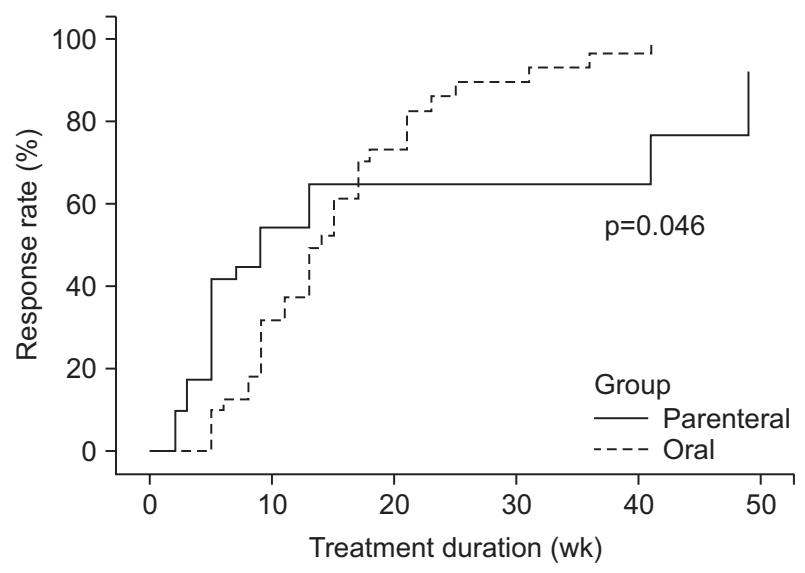

Fig. 4. Comparison of the efficacies of parenteral and oral iron treatment according to the time spent to achieve a $\geq 20 \%$ increase in hemoglobin from the baseline. The data were analyzed using the life table method.

outcome, the rise in $\mathrm{Hb} \geq 2 \mathrm{~g} / \mathrm{dL}$ from the baseline (Table 4). When the same equivalent doses of iron were administered, parenteral iron therapy seemed to be more efficient that oral iron therapy, but it was not statistically significant (hazard ratio [HR], 1.565; 95\% confidence interval [CI], 0.855 to 2.864; $\mathrm{p}=0.146$ ). Patients with UC were good responder to iron therapy (HR, 3.009; 
Table 4. Analysis of the Factors That Affect the Increase in Hemoglobin of $\geq 2 \mathrm{~g} / \mathrm{dL}$ from the Baseline

\begin{tabular}{|c|c|c|c|c|c|c|}
\hline \multirow{2}{*}{ Variable } & \multirow{2}{*}{ No. } & \multirow{2}{*}{ No. of responder $(\%)$} & \multicolumn{2}{|c|}{ Univariate analysis } & \multicolumn{2}{|c|}{ Multivariate analysis } \\
\hline & & & $\mathrm{HR}(95 \% \mathrm{CI})$ & p-value & $\mathrm{HR}(95 \% \mathrm{CI})$ & p-value \\
\hline Age & & & $1.011(0.992-1.031)$ & $0.256^{*}$ & $0.988(0.966-1.010)$ & $0.273^{\dagger}$ \\
\hline \multicolumn{7}{|l|}{ Sex } \\
\hline Male & 40 & $32(80.0)$ & 1.000 & - & 1.000 & - \\
\hline Female & 42 & 27 (64.3) & $0.827(0.494-1.385)$ & $0.471^{*}$ & $0.960(0.561-1.644)$ & $0.882^{\dagger}$ \\
\hline \multicolumn{7}{|c|}{ Route of administration } \\
\hline Oral & 41 & 34 (82.9) & 1.000 & - & 1.000 & - \\
\hline Parenteral & 41 & $25(61.0)$ & $1.576(0.911-2.725)$ & $0.103^{*}$ & 1.565 (0.855-2.864) & $0.146^{\dagger}$ \\
\hline \multicolumn{7}{|l|}{ Type of IBD } \\
\hline Crohn's disease & 54 & 35 (64.8) & 1.000 & - & 1.000 & - \\
\hline Ulcerative colitis & 28 & $24(85.7)$ & $2.431(1.432-4.127)$ & $0.001^{*}$ & 3.099 (1.659-5.789) & $<0.001^{\dagger}$ \\
\hline \multicolumn{7}{|c|}{ Initial hemoglobin, g/dL } \\
\hline Hemoglobin $<10$ & 54 & $41(75.9)$ & 1.000 & - & 1.000 & - \\
\hline Hemoglobin $\geq 10$ & 28 & $18(64.3)$ & $0.580(0.332-1.012)$ & $0.055^{*}$ & $0.449(0.240-0.841)$ & $0.012^{\dagger}$ \\
\hline \multicolumn{7}{|l|}{ Anti-TNF- $\alpha$} \\
\hline No & 76 & $55(72.4)$ & 1.000 & - & 1.000 & - \\
\hline Yes & 6 & $4(66.7)$ & $0.316(0.098-1.021)$ & $0.054^{*}$ & $0.416(0.121-1.425)$ & $0.163^{\dagger}$ \\
\hline
\end{tabular}

HR, hazard ratio; CI, confidence interval; IBD, inflammatory bowel disease; Anti-TNF- $\alpha$, anti-tumor necrosis factor $\alpha$.

*Univariate Cox regression analysis; ${ }^{\dagger}$ Multivariate Cox regression analysis.

Table 5. Analysis of the Factors That Affect the Increase in Hemoglobin of $\geq 20 \%$ from the Baseline

\begin{tabular}{|c|c|c|c|c|c|c|}
\hline \multirow{2}{*}{ Variable } & \multirow{2}{*}{ No. } & \multirow{2}{*}{ No. of responder (\%) } & \multicolumn{2}{|c|}{ Univariate analysis } & \multicolumn{2}{|c|}{ Multivariate analysis } \\
\hline & & & $\operatorname{HR}(95 \% \mathrm{CI})$ & p-value & $\operatorname{HR}(95 \% \mathrm{CI})$ & $\mathrm{p}$-value \\
\hline Age & & & $1.013(0.993-1.033)$ & $0.197^{*}$ & $0.986(0.965-1.008)$ & $0.224^{\dagger}$ \\
\hline \multicolumn{7}{|l|}{ Sex } \\
\hline Male & 40 & $32(80.0)$ & 1.000 & - & 1.000 & - \\
\hline Female & 42 & $27(64.3)$ & $0.794(0.472-1.335)$ & $0.384^{*}$ & $0.910(0.527-1.571)$ & $0.735^{\dagger}$ \\
\hline \multicolumn{7}{|c|}{ Route of administration } \\
\hline Oral & 41 & $34(82.9)$ & 1.000 & - & 1.000 & - \\
\hline Parenteral & 41 & $25(61.0)$ & $1.613(0.929-2.798)$ & $0.089^{*}$ & $1.552(0.844-2.851)$ & $0.157^{\dagger}$ \\
\hline \multicolumn{7}{|l|}{ Type of IBD } \\
\hline Crohn's disease & 54 & $35(64.8)$ & 1.000 & - & 1.000 & - \\
\hline Ulcerative colitis & 28 & $24(85.7)$ & $2.522(1.480-4.298)$ & $0.001^{*}$ & $3.415(1.808-6.450)$ & $<0.001^{\dagger}$ \\
\hline \multicolumn{7}{|c|}{ Initial hemoglobin, g/dL } \\
\hline Hemoglobin $<10$ & 54 & $44(81.5)$ & 1.000 & - & 1.000 & - \\
\hline Hemoglobin $\geq 10$ & 28 & $15(53.6)$ & $0.464(0.257-0.838)$ & $0.011^{*}$ & $0.345(0.177-0.671)$ & $0.002^{\dagger}$ \\
\hline \multicolumn{7}{|l|}{ Anti-TNF- $\alpha$} \\
\hline No & 76 & $54(71.1)$ & 1.000 & - & 1.000 & - \\
\hline Yes & 6 & $5(83.3)$ & $0.327(0.101-1.058)$ & $0.062^{*}$ & $0.427(0.125-1.472)$ & $0.178^{\dagger}$ \\
\hline
\end{tabular}

HR, hazard ratio; CI, confidence interval; IBD, inflammatory bowel disease; Anti-TNF- $\alpha$, anti-tumor necrosis factor $\alpha$.

*Univariate Cox regression analysis; ${ }^{\dagger}$ Multivariate Cox regression analysis.

95\% CI, 1.659 to $5.789 ; \mathrm{p}<0.001)$ and response to iron therapy were poorer when patients' initial $\mathrm{Hb}$ was $10 \mathrm{~g} / \mathrm{dL}$ or higher $(\mathrm{HR}$, 0.449; 95\% CI, 0.240 to $0.841 ; \mathrm{p}=0.012$ ).

Moreover, factors associated with secondary outcome, the rise in $\mathrm{Hb} \geq 20 \%$ from the baseline, were evaluated (Table 5). When the same equivalent doses of iron were administered, patients treated with parenteral iron achieved the secondary outcome more effectively than those with oral iron, but it was not statis- 
tically significant (HR, 1.552; 95\% CI, 0.844 to 2.851 ; $\mathrm{p}=0.157)$. Patients with UC responded better to the iron therapy than those with CD (HR, 3.415; 95\% CI, 1.808 to 6.450; p<0.001). Patients with initial $\mathrm{Hb} 10 \mathrm{~g} / \mathrm{dL}$ or higher responded poorly to iron therapy (HR, 0.345; 95\% CI, 0.177 to $0.671 ; \mathrm{p}=0.002$ ).

\section{DISCUSSION}

In this study, we showed that parenteral iron is more efficient than oral iron in IBD patient. When evaluating the response rate of $\mathrm{Hb}$ rising over $20 \%$ from the baseline, it was higher in oral iron group than parenteral iron group (82.9\% vs 61.0\%). However, patients in parenteral iron group achieved the treatment outcome at the lower total dose and in the shorter duration ( $p=0.034$ and $p=0.046$, respectively). Considering the influence of confounding factors, multivariate analysis was performed to evaluate the overall treatment effect. Parenteral iron therapy seemed to be more efficient than oral iron therapy, but it was not statistically significant (HR, 1.552; 95\% CI, 0.844 to 2.851; $\mathrm{p}=0.157)$. Other factors affected the treatment outcome were type of IBD and Initial $\mathrm{Hb}(\mathrm{HR}, 3.415,95 \% \mathrm{CI}, 1.808$ to 6.450, $\mathrm{p}<0.001$; and HR, 0.345, 95\% CI, 0.177 to $0.671, \mathrm{p}=0.002$, respectively).

We established the primary outcome measure as the rise in $\mathrm{Hb} \geq 2 \mathrm{~g} / \mathrm{dL}$ from the baseline. It was the most widely used criteria in the previous studies to evaluate the treatment response of anemia. However, there was a discrepancy in baseline $\mathrm{Hb}$ between parenteral and oral iron groups in our study. Therefore, it seemed unfair to compare the treatment outcome with the absolute rise in the $\mathrm{Hb}$. Thus, we set the secondary outcome as the rise in $\mathrm{Hb} \geq 20 \%$ from the baseline. As we expected, in the life table method, only the secondary outcome showed the positive results that meant the superiority of parental iron over oral iron.

Interestingly, in this study the patients with UC responded better to the iron therapy than those with $\mathrm{CD}$. Although we performed extensive literature search to find evidence based explanations for our findings, we couldn't find satisfactory explanations. A possible explanation is that $\mathrm{CD}$ patients might have chance that other type of anemia, such as megaloblastic anemia due to vitamin $\mathrm{B}_{12}$ deficiency, was combined, because involvement of terminal ileum was observed in 56\% of CD patients in this study.

Also, our study showed that patients with initial $\mathrm{Hb} 10 \mathrm{~g} /$ $\mathrm{dL}$ or higher responded poorly to iron administration. It is well known that Epo levels are elevated in patients with IDA. ${ }^{22}$ We can infer that serum Epo concentration progressively increased as serum iron concentration decreased. ${ }^{23}$ Therefore, we can erect a hypothesis that patients with severe IDA (initial $\mathrm{Hb}<10 \mathrm{~g} / \mathrm{dL}$ ), might have higher Epo level, and responded better when iron was supplied.

Several randomized controlled trials compared the efficacy of parenteral and oral iron therapy. ${ }^{14-17,24}$ These studies sug- gested that intravenous iron is safe, effective and well tolerated in patients with IBD. In the study by Erichsen et al., ${ }^{17}$ patients in parenteral iron group received $600 \mathrm{mg}$ of elemental iron, on the other hand, patients in oral iron group received 1,680 mg of elemental iron. Considering low bioavailability of oral iron, there would be discrepancy of total dose of iron absorbed. These discrepancy was also observed in the study of Schröder et al., ${ }^{16}$ $1,000 \mathrm{mg}$ to $2,000 \mathrm{mg}$ of parenteral iron versus $8,400 \mathrm{mg}$ to $16,800 \mathrm{mg}$ of oral iron. In the other three studies, ${ }^{14,15,24}$ oral iron was administered in the fixed dose, but parenteral iron was adjusted according to the Ganzoni formula. ${ }^{25}$ These differences in the treated dose of iron, the efficacy of parenteral iron might be misread. So we adopted the concept of equivalent dose, considering the bioavailability of iron, to measure dose-effect relationship according to the route of administration.

Our study provided the valuable information that the efficacy of parenteral iron was superior to oral iron in Asian population, however, present study had several limitations. First, the number of patients involved in this study was relatively small. It reduced the statistical power, thus, we could only observed the trend of better response of parenteral iron but failed to prove this theory statistically in multivariate analysis. Second, inclusion criteria of IDA patients were ambiguous. We included patients with microcytic hypochromic anemia in complete blood count, because many patients did not undergo further diagnostic test like ferritin, transferrin saturation, vitamin $\mathrm{B}_{12}$, folate, and C-reactive protein. Third, as this was a retrospective design, there was no standardized treatment protocol for oral and parenteral iron therapy. Treatment dose, interval and duration of iron therapy were not uniform. Furthermore, follow up interval in the treated patients were not consistent. Forth, the disease activity at the time of iron administration is one of the important factors which attribute to the efficacy of iron therapy; however, we failed to acquire the data about baseline disease activity such as Crohn's disease activity index or Mayo score at the time of iron administration. However, to overcome this limitation, we analyzed the data about concurrent medication at the time of iron administration, because concurrent medications reflect disease activity. At last, we failed to exactly monitor the safety profile of parenteral and oral iron therapy. When we reviewed the medical records, we could not find any description regarding significant adverse events causing morbidity or mortality. However, minor adverse events might be missed.

In conclusion, our study showed that the efficacy of parenteral iron was better than oral iron group in terms of required iron amount and treatment duration. This study suggested the potential advantage of parenteral iron therapy in IBD patients. Physicians should pay attention to the IDA of IBD patients and consider parenteral iron supplement in appropriate patient group. 


\section{CONFLICTS OF INTEREST}

No potential conflict of interest relevant to this article was reported.

\section{REFERENCES}

1. Schreiber S, Howaldt S, Schnoor M, et al. Recombinant erythropoietin for the treatment of anemia in inflammatory bowel disease. N Engl J Med 1996;334:619-623.

2. Cucino C, Sonnenberg A. Cause of death in patients with inflammatory bowel disease. Inflamm Bowel Dis 2001;7:250-255.

3. Pizzi LT, Weston CM, Goldfarb NI, et al. Impact of chronic conditions on quality of life in patients with inflammatory bowel disease. Inflamm Bowel Dis 2006;12:47-52.

4. Wells CW, Lewis S, Barton JR, Corbett S. Effects of changes in hemoglobin level on quality of life and cognitive function in inflammatory bowel disease patients. Inflamm Bowel Dis 2006;12:123130.

5. Cronin CC, Shanahan F. Anemia in patients with chronic inflammatory bowel disease. Am J Gastroenterol 2001;96:2296-2298.

6. Kulnigg S, Gasche C. Systematic review: managing anaemia in Crohn's disease. Aliment Pharmacol Ther 2006;24:1507-1523.

7. Ott C, Liebold A, Takses A, Strauch UG, Obermeier F. High prevalence but insufficient treatment of iron-deficiency anemia in patients with inflammatory bowel disease: results of a populationbased cohort. Gastroenterol Res Pract 2012;2012:595970.

8. Gisbert JP, Bermejo F, Pajares R, et al. Oral and intravenous iron treatment in inflammatory bowel disease: hematological response and quality of life improvement. Inflamm Bowel Dis 2009;15:1485-1491.

9. Danese S, Hoffman C, Vel S, et al. Anaemia from a patient perspective in inflammatory bowel disease: results from the European Federation of Crohn's and Ulcerative Colitis Association's online survey. Eur J Gastroenterol Hepatol 2014;26:1385-1391.

10. Lee TW, Kolber MR, Fedorak RN, van Zanten SV. Iron replacement therapy in inflammatory bowel disease patients with iron deficiency anemia: a systematic review and meta-analysis. J Crohns Colitis 2012;6:267-275.

11. Avni T, Bieber A, Steinmetz T, Leibovici L, Gafter-Gvili A. Treatment of anemia in inflammatory bowel disease: systematic review and meta-analysis. PLoS One 2013;8:e75540.

12. Gasche C, Berstad A, Befrits R, et al. Guidelines on the diagnosis and management of iron deficiency and anemia in inflammatory bowel diseases. Inflamm Bowel Dis 2007;13:1545-1553.

13. Dignass AU, Gasche C, Bettenworth D, et al. European consensus on the diagnosis and management of iron deficiency and anaemia in inflammatory bowel diseases. J Crohns Colitis 2015;9:211-222.

14. Kulnigg S, Stoinov S, Simanenkov V, et al. A novel intravenous iron formulation for treatment of anemia in inflammatory bowel disease: the ferric carboxymaltose (FERINJECT) randomized controlled trial. Am J Gastroenterol 2008;103:1182-1192.

15. Lindgren S, Wikman O, Befrits R, et al. Intravenous iron sucrose is superior to oral iron sulphate for correcting anaemia and restoring iron stores in IBD patients: a randomized, controlled, evaluatorblind, multicentre study. Scand J Gastroenterol 2009;44:838-845.

16. Schröder 0, Mickisch 0, Seidler U, et al. Intravenous iron sucrose versus oral iron supplementation for the treatment of iron deficiency anemia in patients with inflammatory bowel disease: a randomized, controlled, open-label, multicenter study. Am J Gastroenterol 2005;100:2503-2509.

17. Erichsen K, Ulvik RJ, Nysaeter G, et al. Oral ferrous fumarate or intravenous iron sucrose for patients with inflammatory bowel disease. Scand J Gastroenterol 2005;40:1058-1065.

18. Kim YJ. Intravenous iron and oral iron treatment in anemia of inflammatory bowel disease. Intest Res 2013;11:227-228.

19. Ye BD, Jang BI, Jeen YT, et al. Diagnostic guideline of Crohn's disease. Korean J Gastroenterol 2009;53:161-176.

20. Choi CH, Jung SA, Lee BI, et al. Diagnostic guideline of ulcerative colitis. Korean J Gastroenterol 2009;53:145-160.

21. Geisser P, Burckhardt S. The pharmacokinetics and pharmacodynamics of iron preparations. Pharmaceutics 2011;3:12-33.

22. Kaushansky K, Lichtman MA, Beutler E, Kipps TJ, Seligsohn U, Prchal JT. Williams Hematology. 8th ed. New York: McGraw-Hill Education LLC, 2010.

23. Naito Y, Tsujino T, Matsumoto M, Sakoda T, Ohyanagi M, Masuyama T. Adaptive response of the heart to long-term anemia induced by iron deficiency. Am J Physiol Heart Circ Physiol 2009; 296:H585-H593.

24. Reinisch W, Staun M, Tandon RK, et al. A randomized, openlabel, non-inferiority study of intravenous iron isomaltoside 1,000 (Monofer) compared with oral iron for treatment of anemia in IBD (Proceed). Am J Gastroenterol 2013;108:1877-1888.

25. Ganzoni AM. Intravenous iron-dextran: therapeutic and experimental possibilities. Schweiz Med Wochenschr 1970;100:301-303. 